\title{
Avaliação de parâmetros para o diagnóstico laboratorial de infecção genital feminina pela Chlamydia trachomatis
}

\author{
Evaluation of parameters for laboratory diagnosis of genital \\ female infection by Chlamydia trachomatis
}

\author{
Heloisa Helena Barbosa Melles ${ }^{1}$, Silvia Colombo', lara Moreno Linhares ${ }^{2}$ \\ e Luiz Fernando de Góez Siqueira ${ }^{3}$
}

\begin{abstract}
Resumo Foram examinadas prospectivamente189 amostras cervicais de mulheres sintomáticas e assintomáticas. Foram colhidas 2 amostras do canal endocervical, das quais uma foi examinada pela reação de imunofluorescência direta (IFD) com anticorpo monoclonal (MicroTrak), para verificação da adequação das amostras. A segunda amostra foi inoculada em cultura de células McCoy. Uma terceira amostra foi coletada para pesquisa de anticorpos das classes $\lg G$ e $\lg A$. A Chlamydia trachomatis foi isolada de $14 / 166(8,4 \%)$ das mulheres com sintomas e de $3 / 23(13 \%)$ daquelas sem sintomas. Observamos que as 152 mulheres do grupo sintomático, com cultura negativa, possuiam sintomas equivalentes. Em relação ao número de células epiteliais, verificou-se que 13 das 17 (76,5\%) amostras endocervicais positivas pela cultura e pela IFD, todas apresentavam mais de 5 células. Tomando-se como critério de positividade títulos 1 1:8, foram detectados anticorpos das classes IgG e/ou IgA específicos para C. trachomatis em 11/189 (64,7\%) das 17 mulheres com cultura positiva. Conclusões: a) não existe sintoma que seja específico de infecção por clamídia $(p>0,05)$; b) a quantidade de células epiteliais representariam fator de interferência na positividade da cultura, sendo, portanto, variáveis dependentes $(p<0,001)$; $c)$ a pesquisa de anticorpos na cérvice não poderia ser utilizada como diagnóstico alternativo, pois a sua detecção depende da fase evolutiva da infecção e da resposta imunitária individual.
\end{abstract}

Palavras-chaves: Chlamydia trachomatis. Diagnóstico laboratorial. Infecção genital. Isolamento. Anticorpos.

\begin{abstract}
In order to evaluate the occurrence of Chlamydia trachomatis, we have examined samples of cervical swabs from 189 women (166 of which were symptomatic and the remaining 23 were asymptomatic with regard to chlamydial infection. Two specimens from the endocervical channel were collected and examined by immunofluorescent assay (DIF) and Chlamydia isolation. Detection of IgG and $\lg A$ antibodies specific to $\mathrm{C}$. trachomatis was also effected by indirect immunofluorescent assay (IIF), in a cervical secretion sample. We succeeded in isolating chlamydia in 14 (8.4\%) symptomatic and $3(13 \%)$ asymptomatic women. The observation that the 152 symptomatic patients with negative results from chlamydia culture presented similar symptoms of disease, indicating that there is no specific symptom for genital infection caused by Chlamydia $(p>0.05)$. All the $13(76.5 \%)$ positive endocervical specimens, as determined by cell culture and DIF reaction, presented more than 5 epithelial cells in the smears. These cells may represent an interference factor to the positivity of cell culture $(p<0.001)$. Antibodies of the IgG and/or IgA classes were detected in 11 (64.7\%) out of 17 women with positive chlamydia culture, considering as positive the IIF titre of $\bullet$. Consequently, this method can not be used as an alternative means of diagnosis, particularly in the earlier stages of chlamydial genital infections, since the presence of the antibodies depends on the phase of the infection and on the individual humoral immune response.
\end{abstract}

Key-words: Chlamydia trachomatis. Laboratory diagnosis. Genital infection. Antibodies. Isolation.

1. Setor de Riquétsias, Serviço de Virologia do Instituto Adolfo Lutz; 2. Ambulatório de Ginecologia e Obstetrícia do Hospital das Clínicas da Universidade de São Paulo; 3. Serviço de Dermatologia Sanitária, Faculdade de Higiene e Saúde Pública da Universidade de São Paulo. Endereço para correspondência: Dra. Heloisa Helena B. Melles, PqC-V, Serviço de Virologia, Instituto Adolfo Lutz, Av. Dr. Arnaldo, 355Cerqueira Cesar, 01246-902 São Paulo, SP, Brasil.

Telefax: 5511 280-3753.

e-mail: Heloisahbmelles@Hotmail.com.

Recebido para publicação em 19/1/99. 
A Chlamydia trachomatis tem sido considerada uma das causas mais comuns de uretrite não gonocócica nos homens e de cervicite nas mulheres.

Mulheres infectadas pela $C$. trachomatis podem apresentar ou não sintomas específicos ou então não apresentar quaisquer sinais ou sintomas visíveis da infecção ${ }^{2}{ }^{8}$. Diferentes publicações citam a associação da $C$. trachomatis à doenças sexualmente transmissíveis (DST) que não a gonorréia, não só entre os homens mas também entre as mulheres. Para aquelas que apresentam algum sintoma o isolamento da clamídia tem sido de 5 a $19 \%$ dos $\operatorname{casos}^{1823}$, enquanto que para as mulheres assintomáticas essa percentagem varia de 3,5 a $8 \%^{621}$.

$\mathrm{O}$ aprimoramento de métodos laboratoriais permitiu um grande avanço no diagnóstico e avaliação epidemiológica das infecções provocadas pela C. trachomatis. A técnica de cultura celular introduzida por Gordon e Quan utilizando células irradiadas, foi um marco no diagnóstico das infecções por clamídia ${ }^{9}$. A aplicação de drogas citostáticas em lugar da irradiação como prétratamento das células hospedeiras promove a redução do metabolismo dessas células, proporcionando condições mais favoráveis ao desenvolvimento do parasita ${ }^{2122} 28$. O método mais aplicado para isolamento da $C$. trachomatis na atualidade é o tratamento da célula McCoy com a cycloheximida, droga citostática que permite a utilização de células em plena atividade metabólica, com apenas $24 \mathrm{~h}$ de incubação, tornando-as mais sensíveis ao desenvolvimento da clamídia ${ }^{21}$.

$\mathrm{Na}$ coleta da amostra, quer para fins citológicos, quer para fins de isolamento, deve- se sempre considerar a quantidade de células epiteliais contidas nesse material ${ }^{19}$, levando-se em conta que a clamídia é um microrganismo intracelular obrigatório, com preferência por células do epitélio colunar. Assim, a presença dessas células reflete a qualidade da amostra para diagnóstico laboratorial.

Anticorpos anticlamídia de mucosa, principalmente os da classe IgA, podem ser indicativos de infecção ativa corrente pela $C$. trachomatis, estando correlacionado com seu isolamento da cérvice ${ }^{15} 20$. No entanto, o valor diagnóstico da determinação de tais anticorpos pode ser menor pelo fato de que anticorpos $\lg \mathrm{A}$ uretrais persistem por vários anos e existe uma alta prevalência de anticorpos locais em populações de clínicas de doenças sexualmente transmissíveis ${ }^{25}$.

A cultura em células, comparada aos testes de detecção direta de antígeno, é o método padrão de diagnóstico de infecção pela $C$. trachomatis no trato genital masculino e feminino ${ }^{27}$.

Realizamos este estudo tendo como objetivos:

a) avaliar os resultados obtidos na cultura de células e relacioná-los com os dados de sintomatologia que pudessem ser considerados como hipótese diagnóstica;

b) avaliar a presença e quantidade de células epiteliais no raspado cervical que pudesse ser considerada como fator de interferência no isolamento de clamídia;

c) avaliar a detecção de anticorpos IgG e/ou IgA na secreção cervical específicos para $C$. trachomatis, que pudesse ser utilizada como diagnóstico alternativo, substituindo o isolamento em cultura celular;

\section{MATERIAL E MÉTODOS}

Carecterísticas da população. Foram trabalhados os materiais endocervicais de 189 mulheres, que compareceram ao Ambulatório de Ginecologia do Hospital das Clínicas da Universidade de São Paulo, onde foram colhidas as amostras e separadas em 2 grupos. A população identificada como A era composta de 166 mulheres sintomáticas, ou seja, que no momento da consulta apresentavam algum sintoma de afecção ginecológica. A população B era composta de 23 mulheres que não apresentavam nenhum sinal ou sintoma de doença urogenital, sendo, portanto, assintomáticas.
De todos os casos foi colhido material endocervical para pesquisa de $C$. trachomatis pelo exame direto e cultura, e ainda, de secreção cervical para detecção de anticorpos $\lg G$ e $\lg A$ específicos para C. trachomatis.

Um protocolo em forma de questionário, contendo dados de anamnese ginecológica e obstétrica, atividade sexual e queixa ginecológica principal no momento da consulta, foi feito para cada caso selecionado para o estudo.

Isolamento de C. trachomatis. As amostras de material endocervical foram colhidas com swab de algodão alginatado que introduzido no 
canal endocervical, com movimentos rotatórios, foi em seguida colocado em tubos contendo meio de transporte $2 \mathrm{SP}^{1}$. As amostras foram posteriormente inoculadas, em duplicata, nos tubos de cultura de células McCoy preparadas sobre lamínulas circulares. Os tubos de cultura foram centrifugados a $2500 \mathrm{xg}$ a $30^{\circ} \mathrm{C}$ por 1 hora. Após a centrifugação, foi retirado o inóculo e adicionado $1 \mathrm{ml}$ de Meio Mínimo de Eagle modificado suplementado com cycloheximida $(2 \mu \mathrm{g} / \mathrm{ml})^{21}$.

A identificação do isolamento microbiano foi realizada na própria lamínula, utilizando a reação de imunofluorescência indireta (IFI). Empregouse como anticorpo, soro humano imune para LGV (Lymphogranuloma Venereum) e como revelador da reação, soro anti-lgG humano conjugado à fluoresceína ${ }^{1718}$. A reação foi realizada somente em um dos tubos, sendo o outro utilizado para processar passagem sucessiva em novos tubos de cultura de células. Foram consideradas positivas as culturas que apresentaram uma ou mais inclusões típicas, quando a intensidade de fluorescência em toda a lamínula fosse de 2 cruzes $(++)$ ou mais, numa escala de 0 a 4 cruzes. Foram consideradas negativas as culturas que, após a segunda passagem, não evidenciaram qualquer inclusão ${ }^{3}$.

Exame direto. Após o processamento do material destinado ao isolamento microbiano, o mesmo swab foi novamente introduzido no canal endocervical e o material obtido foi impresso, por decalque, no espaço delimitado de uma lâmina própria para aplicação do MicroTrak test da Syva Com. As lâminas assim preparadas foram fixadas e coradas de acordo com as recomendações do fabricante, e examinadas em microscópio de fluorescência com epi-iluminação (Nikon-YB-EFIII). Avaliou-se nos esfregaços a presença de corpúsculos elementares (CEs) verdes fluorescentes e o número de células epiteliais presentes. De acordo com esta última variável, os esfregaços foram assim classificados: a) sem células epiteliais; b) com 1 a 4 células; c) com 5 a 9 células e d) com 10 ou mais células epiteliais, sendo considerados adequados os materiais com mais de 5 células nos esfregaços ${ }^{19}$.

Pesquisa de anticorpos nas secreções cervicais. Amostras de secreção cervical destinadas à pesquisa de anticorpos $\lg G$ e $\lg A$ foram coletadas de todas as mulheres em estudo. Utilizou-se tiras de papel de filtro de $5 \times 20 \mathrm{~mm}$, que, colocadas de encontro à parede do colo uterino, ficaram saturadas de secreção ${ }^{5}$. Cada tira de papel foi eluída em $0,2 \mathrm{ml}$ de tampão fosfato (PBS) $0,1 \mathrm{M}$ e pH 7,2, deixando a preparação a uma diluição aproximada de 1:8. A pesquisa dos anticorpos foi feita pela reação de imunofluorescência indireta, utilizando-se como antígeno as inclusões produzidas pela amostra L2-434 da C. trachomatis em cultura de células McCoy, conforme técnica descrita por e Smith et al, com a introdução de algumas modificações ${ }^{1622}$.

Para aplicação do teste utilizou-se duas lâminas próprias para imunofluorescência, que continham o antígeno descrito. Em cada lâmina foi depositado, no espaço delimitado, uma gota da secreção cervical diluída a 1:8. Após incubação por $30 \mathrm{~min}$ a $37^{\circ} \mathrm{C}$ em câmara úmida, foram colocados, respectivamente, em cada uma das duas lâminas, anticorpos anti-lgG e anti-lgA humanos conjugados à fluoresceína. Foram consideradas positivas as reações cuja intensidade de fluorescência das inclusões foi maior ou igual a duas cruzes (++) numa escala de 0 a 4 cruzes $^{14}$. Um controle das células McCoy não infectadas foi feito em paralelo.

Análise estatística. Os resultados obtidos pela cultura, relacionados à presença ou não de sintomas e número de células epiteliais nos esfregaços foram comparados pelo teste $\chi^{226}$.

\section{RESULTADOS}

As mulheres das duas populações estudadas eram sexualmente ativas e não gestantes.

A idade das mulheres variou de 22 a 57 anos.

Dos 166 casos com sintomatologia, 56 $(33,7 \%)$ apresentavam apenas corrimento vaginal (leucorréia), outros $31(18,7 \%)$ corrimento vaginal mais prurido. Trinta $(18,1 \%)$ deles apresentavam corrimento vaginal com dor pélvica e $48(28,9 \%)$ corrimento vaginal mais prurido e dor pélvica. Uma das mulheres $(0,6 \%)$ apresentava outros sintomas que não os citados (Tabela 1).

As lâminas preparadas segundo a metodologia descrita foram avaliadas quanto à presença de CEs fluorescentes, de muco e particularmente quanto ao número de células epiteliais.

Na população A (sintomática) verificamos que $13 / 166(7,8 \%)$ mulheres tinham de 1 a 10 CEs nos esfregaços endocervicais, sendo que nas 153 
Tabela 1 - Número e percentagem dos resultados da cultura em relação aos tipos de sintomas isolados ou associados das 166 mulheres da população $A$.

\begin{tabular}{|c|c|c|c|c|c|c|c|c|c|c|c|c|}
\hline \multirow{3}{*}{ Cultura } & \multicolumn{10}{|c|}{ Sintomas } & & \\
\hline & \multicolumn{2}{|c|}{ nenhum } & \multicolumn{2}{|c|}{ CV } & \multicolumn{2}{|c|}{$C V+D P$} & \multicolumn{2}{|c|}{$C V+P R$} & \multicolumn{2}{|c|}{$C V+D P+P R$} & \multicolumn{2}{|c|}{ subtotal } \\
\hline & $\mathrm{n}^{\circ}$ & $\%$ & $\mathrm{n}^{0}$ & $\%$ & $\mathrm{n}^{\circ}$ & $\%$ & $\mathrm{n}^{\circ}$ & $\%$ & $\mathrm{n}^{0}$ & $\%$ & $\mathrm{n}^{0}$ & $\%$ \\
\hline negativa & $1^{*}$ & 0,6 & 54 & 32,5 & 26 & 15,7 & 28 & 16,9 & 43 & 25,9 & 152 & 91,6 \\
\hline positiva & - & - & 2 & 1,2 & 4 & 2,4 & 3 & 1,8 & 5 & 3 & 14 & 8,4 \\
\hline Total & 1 & 0,6 & 56 & 33,7 & 30 & 18,1 & 31 & 18,7 & 48 & 28,9 & 166 & 100 \\
\hline
\end{tabular}

$\mathrm{CV}=$ corrimento vaginal; $\mathrm{PR}=$ prurido; $\mathrm{DP}$ = dor pélvica; * número; - ausência de ocorrência.

restantes não foi encontrado nenhum $\mathrm{CE}$. Da população $B$ (assintomática), em apenas 1/23 $(4,3 \%)$ foram observados 10 ou mais CEs, enquanto as demais não apresentaram esses corpúsculos. Verificamos que existe relação quase direta entre o número de CEs presentes no material endocervical e a presença de células epiteliais, pois, com exceção de $1(0,6 \%)$ dos esfregaços da população $A$, todos os demais que apresentavam CEs fluorescentes, tinham mais de 5 células epiteliais.

A C. trachomatis foi isolada do material endocervical de 14 (8,4\%) mulheres do grupo das 166 mulheres consideradas sintomáticas, enquanto que as assintomáticas, $3 / 23$ (13\%) tiveram a cultura positiva para esse agente etiológico.

Nas secreções das 189 mulheres da população estudada foi detectada a presença de anticorpos da classe lgG em 9 (4,7\%) e 7 (3,7\%) delas tinham anticorpos da classe lgA.
Relação entre os resultados da cultura e dados utilizados como hipótese diagnóstica, fatores de interferência e outras alternativas diagnósticas. Relação cultura e sintomas. A Tabela 1 mostra, em número e percentual, a relação entre a positividade da cultura e os sintomas apresentados pelas mulheres da população A. Observamos que aquelas mulheres com cultura positiva para $C$. trachomatis tinham corrimento vaginal, isoladamente $(1,2 \%)$ ou associado a outro sintoma, somando $7,2 \%$. 0 sintoma correspondente à maior percentagem de positivos pela cultura foi o corrimento vaginal com prurido mais dor pélvica (3\%), entretanto, podese observar também corrimento vaginal em $91,6 \%$ das mulheres com cultura negativa.

Relação cultura e número de células epitelias. A Tabela 2 mostra que 17/189 (8,9\%) das mulheres das 2 populações estudadas, para as quais a cultura foi positiva para $C$. trachomatis, apresentaram mais de 5 células epiteliais no esfregaço endocervical. Verificamos que 84

Tabela 2 - Relação em número e percentagem entre os resultados da cultura e o número de células epiteliais nos esfregaços encocervicais das mulheres das duas populações.

\begin{tabular}{|c|c|c|c|c|c|c|c|c|c|c|c|c|}
\hline \multirow{4}{*}{$\begin{array}{l}\text { Número de } \\
\text { células } \\
\text { epiteliais }\end{array}$} & \multicolumn{6}{|c|}{ População A = 166} & \multicolumn{6}{|c|}{ População $B=23$} \\
\hline & \multicolumn{6}{|c|}{ cultura } & \multicolumn{6}{|c|}{ cultura } \\
\hline & \multicolumn{2}{|c|}{ negativa } & \multicolumn{2}{|c|}{ positiva } & \multicolumn{2}{|c|}{ total } & \multicolumn{2}{|c|}{ negativa } & \multicolumn{2}{|c|}{ positiva } & \multicolumn{2}{|c|}{ total } \\
\hline & $\mathrm{n}^{0}$ & $\%$ & $\mathrm{n}^{\circ}$ & $\%$ & $\mathrm{n}^{\circ}$ & $\%$ & $\mathrm{n}^{\circ}$ & $\%$ & $\mathrm{n}^{0}$ & $\%$ & $\mathrm{n}^{0}$ & $\%$ \\
\hline 0 & $10^{*}$ & 6 & - & - & 10 & 6 & 7 & 30,4 & - & - & 7 & 30,4 \\
\hline $1-4$ & 74 & 44,6 & - & & 74 & 44,6 & 9 & 39,2 & - & - & 9 & 39,2 \\
\hline $5-9$ & 57 & 34,4 & 9 & 5,4 & 66 & 39,8 & 1 & 4,3 & 2 & 8,7 & 3 & 13 \\
\hline - 10 & 11 & 6,6 & 5 & 3 & 16 & 9,6 & 3 & 13 & 1 & 4,3 & 4 & 17,4 \\
\hline Total & 152 & 91,6 & 14 & 8,4 & 166 & 100 & 20 & 13 & 3 & 4,3 & 23 & 100 \\
\hline
\end{tabular}

* número; - ausência de ocorrência

(54,5\%) das amostras da população A em que a cultura foi negativa, tinham menos de 5 células epitelais nos esfregaços. Observação semelhante foi feita na população $B$, isto é, $16 / 23(80 \%)$ dos esfregaços cujas amostras foram negativas na cultura apresentavam menos de 5 células epiteliais.
Relação cultura e anticorpos nas secreções cervicais. Com relação aos resultados da cultura e a presença de anticorpos cervicais IgG e/ou IgA detectados nas secreções endocervicais colhidas das duas populações, verificamos que das mulheres com cultura positiva, em 4/17 $(23,5 \%)$ foram detectados apenas anticorpos da 
classe IgA; em outras 4/17 (23,5\%) apenas IgG. Anticorpos IgG e IgA foram detectados em 3/17 $(17,6 \%)$. Nas secreções das 6/17 (35,3\%) mulheres restantes, não foram detectados anticorpos de nenhuma das classes de imunoglobulinas avaliadas. Desta forma, das 17 mulheres que tinham cultura positiva para C. trachomatis os anticorpos das classes IgG e/ou IgA puderam ser detectados em $11(64,7 \%)$ delas (Tabela 3). Nas mulheres com cultura negativa não foram detectados esses anticorpos.

Tabela 3 - Relação em número e percentagem, dos resultados da cultura e o título de anticorpos IgG e/ou IgA específicos para C. trachomatis nas secreçoes cervicais das 189 mulheres da população estudada.

\begin{tabular}{|c|c|c|c|c|c|c|c|c|c|c|c|c|}
\hline \multirow{4}{*}{$\begin{array}{l}\text { Título } \\
\text { de } \\
\lg A\end{array}$} & \multicolumn{6}{|c|}{ Cultura negativa } & \multicolumn{6}{|c|}{ Cultura positiva } \\
\hline & \multirow{2}{*}{\multicolumn{2}{|c|}{$\begin{array}{c}\text { títulos } \\
>8\end{array}$}} & \multirow{2}{*}{\multicolumn{2}{|c|}{$\begin{array}{c}\text { de } \lg G \\
\cdot 8\end{array}$}} & \multirow{2}{*}{\multicolumn{2}{|c|}{ Total }} & \multirow{2}{*}{\multicolumn{2}{|c|}{$\begin{array}{c}\text { títulos } \\
>8\end{array}$}} & \multirow{2}{*}{\multicolumn{2}{|c|}{$\begin{array}{c}\text { de } \lg G \\
\cdot 8\end{array}$}} & \multirow{2}{*}{\multicolumn{2}{|c|}{ Total }} \\
\hline & & & & & & & & & & & & \\
\hline & $\mathrm{n}^{0}$ & $\%$ & $\mathrm{n}^{0}$ & $\%$ & $\mathrm{n}^{\circ}$ & $\%$ & $\mathrm{n}^{\circ}$ & $\%$ & $\mathrm{n}^{\circ}$ & $\%$ & $\mathrm{n}^{\circ}$ & $\%$ \\
\hline$<8$ & $170^{*}$ & 98,8 & 2 & 1,2 & 172 & 100 & 6 & 35,3 & 4 & 23,5 & 10 & 58,8 \\
\hline .8 & - & - & - & - & - & - & 4 & 23,5 & 3 & 17,6 & 7 & 41,2 \\
\hline Total & 170 & 98,8 & 2 & 1,2 & 172 & 100 & 10 & 58,8 & 7 & 41,2 & 17 & 100 \\
\hline
\end{tabular}

$<8$ = Negativo; $\bullet 8$ = Positivo; * número; - Ausência de ocorrência.

\section{DISCUSSÃO}

Tem sido demonstrado que mulheres com infecções cervicais pela $C$. trachomatis não apresentam qualquer sinal ou sintoma clínico característico, embora se tenha verificado que pelo menos alguns casos poderiam apresentar cervicite folicular característica ${ }^{18}$.

Em nosso trabalho verificamos que das 14 $(8,4 \%)$ mulheres da população A (sintomática) com cultura positiva, todas apresentavam queixa de corrimento vaginal isolado ou associado a prurido e/ou dor pélvica. No entanto, verificamos que as 152 mulheres com cultura negativa para clamídia, também apresentavam os mesmos sintomas (Tabela 1). Assim, reafirmamos a conclusão de autores de que não existe, de fato, sintoma que se possa dizer específico de infecção genital pela $C$. trachomatis ${ }^{11}$.

O fato de termos obtido $13 \%$ de positividade pela cultura na população $B$ (assintomática), pouco mais elevada que na população $A$ (sintomática) 8,4\%, não deve ser tomado como relevante, considerando-se as características da população estudada e os critérios adotados para distribuição das mulheres nas duas populações. A aplicação do teste $\chi^{2}$ demonstrou que essa diferença não foi significativa $(p>0,05)$ e que, portanto, as variáveis positividade da cultura e sintomas são independentes, ou seja, as freqüências de positividade para infecção por clamídia são equivalentes na presença ou não de sintomas.

Entre a população estudada, 2 mulheres referiram contato sexual com parceiros que apresentavam doença genitourinária.
Considerando os critérios adotados para separação dos casos e ainda aliado ao fato de não termos tido acesso a esses parceiros, incluímos essas mulheres ao grupo assintomático. O mesmo procedimento também já havia sido tomado por Sorbie e Shaughnessy ${ }^{24}$.

$\mathrm{Na}$ avaliação dos resultados dos exames laboratoriais a relação cultura e número de células epiteliais deve ser considerada quando se deseja pesquisar a $C$. trachomatis tanto nos olhos como no trato genital, pois a clamídia infecta essas células $^{1219}$. Considerando a presença de células epiteliais como critério de adequação da amostragem, Phillips et $\mathrm{al}^{19}$, verificaram que a sensibilidade da reação de imunofluorescência foi de $40 \%$ para as lâminas que tinham menos de 5 células epiteliais e de $92 \%$ quando estavam presentes 5 ou mais células. Em nosso trabalho, para essa mesma relação a sensibilidade foi de $7,6 \%$ e $92,3 \%$ respectivamente. Na impossibilidade de contagem das células na amostra colhida para cultura, analisamos, de forma cruzada, os resultados obtidos em relação ao número de células epiteliais contidas nos esfregaços endocervicais das mulheres das duas populações, considerando-se que as amostras positivas na cultura foram também positivas na imunofluorescência direta. Observamos que, as amostras das 2 populações positivas na cultura, isto é, $17 / 189(8,9 \%)$ apresentavam mais de 5 células epiteliais nos esfregaços (Tabela 2). Pelos nossos resultados podemos, portanto, inferir que é possível extrapolar os achados de células 
epiteliais, pela IFD para a cultura e que o número de células representariam fator de interferência na positividade da cultura. Para confirmar, aplicando o teste do $\chi^{2}$, verificamos que a variação é significativa $(p<0,001)$, isto é, que as variáveis cultura (positiva ou negativa) e número de células epitelias, são dependentes.

$O$ isolamento da $C$. trachomatis em cultura de células não constitue padrão ouro com $100 \%$ de especificidade e sensibilidade. Entretanto, se processado sob condições ótimas, é mais sensível que os métodos novos e é específico ${ }^{414}$.

A identificação dos microrganismos na cultura foi realizada pela técnica de imunofluorescência indireta utilizando como anticorpo, soro humano imune para LGV. Tem-se demonstrado que os sorotipos L1, L2, L3 e E da C. trachomatis possuem um antígeno proteico que, quando extraído e inoculado em coelho este responde imunológicamente produzindo anticorpos que reagem com a proteína predominante da membrana externa dos 15 sorotipos da $C$. trachomatis. A espécie-especificidade desse anti-soro é demonstrada pela reação de imunofluorescência ${ }^{13}$.

Vários estudos utilizando a cultura para isolamento da $C$. trachomatis descrevem a associação desse agente etiológico com doenças sexualmente transmitidas, não gonocócicas, na mulher.

Nossos resultados mostram positividade de $8,4 \%$ nas mulheres da população $A$ (sintomáticas) e de $13 \%$ naquelas da população $B$ (assintomáticas). Levando em conta o fato de que 2 dos casos da população B, já citado, eram contato de parceiros possivelmente infectados com clamídia, teríamos duas proposições: retirar do estudo esses dois casos porque não tinhamos confirmação da doença nos contatos, assim teríamos $8,4 \%$ de positividade na população $\mathrm{A}$ e $4,8 \%$ na população $\mathrm{B}$; ou anexar esses dois casos à população $\mathrm{A} e$, desta forma os percentuais de positividade da cultura seriam de $9,5 \%$ e $4,8 \%$ nas populações $\mathrm{A}$ e $\mathrm{B}$ respectivamente.

Como discutido anteriomente, optamos por mantê-las na população B tendo em vista a proposta inicial do estudo, e a hipótese de que na pesquisa da $C$. trachomatis em trato genital feminino, a sintomatologia não é fator de exclusão ${ }^{10}$.

A presença de anticorpos das classes IgG e $\lg A$, específicos para $C$. trachomatis, nas secreções cervicais de mulheres infectadas por esse agente, é avaliada por vários autores, porém a verdadeira origem desses anticorpos não está bem esclarecida. Para alguns seriam da própria cérvice, porém, outros acreditam que a origem desses anticorpos seja sérica. Entretanto, todos sugerem que a presença de anticorpos $\lg \mathrm{G}$ e/ou $\lg A$ específicos, na secreção cervical, em título $\bullet 1: 8$, seria indicativo de infecção pela $C$. trachomatis e que, portanto, poderia ser considerado como diagnóstico alternativo de infecção por esse agente ${ }^{5715}$. Nossos resultados revelaram que $11 / 17(64,7 \%)$ das mulheres com isolamento de clamídia na cérvice uterina, apresentavam anticorpos IgG e/ ou IgA (Tabela 3). Em duas amostras que apresentaram, nas secreções, anticorpos da classe IgG, e cujas culturas foram negativas, estes seriam provavelmente de origem sérica, podendo referir a infecção anterior e decorrer de sangramento da cérvice no momento da coleta da secreção.

Apesar de havermos observado que $64,7 \%$ das mulheres com cultura positiva para $C$. trachomatis apresentavam anticorpos $\lg \mathrm{g}$ e/ou $\lg A$ nas secreções cervicais, a sua detecção é dependente da fase evolutiva da infecção e da resposta imunitária individual ${ }^{513}$.

Deste estudo podemos concluir que não existe sintoma que seja específico de infecção pela $C$. trachomatis, portanto, este parâmetro não deve ser utilizado como hipótese diagnóstica. A presença de células epiteliais no material endocervical representa um parâmetro diretamente proporcional ao isolamento da clamídia do trato genital, sendo, portanto, um fator de interferência no resultado da cultura. A presença de anticorpos IgG e/ou IgA na secreção cervical não poderia ser utilizada como diagnóstico alternativo, embora, de forma restrita, devido a baixa sensibilidade na determinação de tais anticorpos, não dispensando, portanto, a utilização de outro método mais sensível.

\section{AGRADECIMENTOS}

À Lina Cristina, Técnico de Apoio à Pesquisa Científica e Tecnológica pela colaboração técnica prestada. À Seção de Cultura Celular do Instituto Adolfo Lutz pelo fornecimento das culturas de células. 


\section{REFERÊNCIAS BIBLIOGRÁFICAS}

1. Aarnaes SL, Peterson EM, DeLa Maza LM. The effect of media and temperature on the storage of Chlamydia trachomatis. American Journal of Clinical Pathology 81:237-239, 1984.

2. Arya OP, Mallinson H, Goddard AD. Epidemiological and clinical correlates of chlamydial infection of the cervix. British Journal of Venereal Diseases 57:118-124, 1981.

3. Bird BR, Forrester FT. Laboratory diagnosis of a Chlamydia trachomatis infections. Atlanta, GA, Centers for Diseases Control, p. 27-71, 1981.

4. Black CM. Current methods of laboratory diagnosis of Chlamydia trachomatis infections. Clinical Microbiology Reviews 10:160-184, 1997.

5. Brunham RC, Kuo CC, Cles L, Holmes KK. Correlation of host immune response with quantitative recovery of Chlamydia trachomatis from the endocervix. Infection and Immunity 39:1491-1494, 1983.

6. Burns DCM, Darougar S, Thin RN, Lothian L, Nicol CS. Isolation of Chlamydia trachomatis from women attending a clinic for sexually transmitted diseases. British Journal of Venereal Diseases 51:314-318, 1975.

7. Chipperfield EJ, Evans BA. Effect of local infection and oral contraception on immunoglobulins levels in cervical mucus. Infection and Immunity 11:215-221, 1975.

8. Ghadirian FD, Robson HG. Chlamydia trachomatis genital infections. British Journal of Venereal Diseases 55:415418, 1979.

9. Gordon FB, Quan AL. Isolation of the trachoma agent in cell culture. Procedures of Society for Experimental Biology and Medicine 118:354-359, 1965.

10. Johannisson G, Lowagen GB, Lycke E. Genital Chlamydia trachomatis infection in women. Obstetris and Ginecology 56:671-675, 1980.

11. Kovacs GT, Westcott M, Rusden J, Asche V, King H, Haynes SE, Moore EK, Ketelbey JW. The prevalence of Chlamydia trachomatis in a young,sexually-active population. Medical Journal of Australia 147:550-554, 1987.

12. Lipkin ES, Moncada JV, Shafer MA, Wilson TE, Schachter J. Comparison of monoclonal antibody stainning and culture in diagnosing cervical chlamydial infection. Journal of Clinical Microbiology 23:114-117, 1986.

13. MacDonald AD. Antigens of Chlamydia trachomatis. Reviews of Infectious Diseases 7:731-736, 1985.

14. Magder L, Klontz KC, Bush LH, Barnes RC. Effect of patient characteristics on performance of an Enzyme immunoassay for detecting cervical Chlamydia trachomatis infection. Journal of Clinical Microbiology 28:781-784, 1990.

15. McComb DE, Nichols RL, Semine DZ, Evrard JR, Alpert S, Crockett VA, Rosner B, Zinner SH, McCormack WM.
Chlamydia trachomatis in women: Antibody in cervical secretions as a possible indicator of genital infection. Journal of Infectious Diseases 139:628-633, 1979.

16. Melles HHB, Colombo S, Ejzemberg B. Pneumonia infantil por Chlamydia trachomatis: diagnóstico sorológico específico. Revista do Instituto Adolfo Lutz 48:57-62, 1988.

17. Munday PE, Johnson AP, Thomas BJ, Taylor-Robson DA. Comparison of sensitivity of immunofluorescence and giemsa for Chlamydia trachomatis. Journal of Clinical Pathology 33:177-179, 1980.

18. Nayyar KC, O'Neill JJ, Hambling MH, Waugh MA. Isolation of Chlamydia trachomatis from women attending a clinic for sexually transmitted diseases. British Journal of Venereal Diseases 52:396- 398, 1976.

19. Phillips RS, Hanff PA, Kauffman RS, Aronson MD. Use of a direct fluorescent antibody test for detecting Chlamydia trachomatis cervical infection in women seeking routine gynecologic care. Journal of Infectious Diseases 156:575-581, 1987.

20. Richmond SY, Milne JD, Hilton AL, Caul EO Antibodies to Chlamydia trachomatis in cervico-vaginal secretions. Relation to serum antibodies and current infection. Sexually Transmitted Diseases 7:11-15, 1980.

21. Ripa, KT, Mardh, PA. Cultivation of Chlamydia trachomatis in cycloheximide-treated Mccoy cells. Journal of Clinical Microbiology 6:328-331, 1977.

22. Smith TF, Brown SD, Weed LA. Diagnosis of Chlamydia trachomatisinfections by cell cultures and serology. Laboratory and Medicine 13:92-100, 1982.

23. Sompolinsk D, Richmond S. Growth of Chlamydia trachomatis in McCoy cells treated with cytochalasian B. Applied Microbiology 28:912- 914, 1974.

24. Sorbie J, Shaughnessy MV. Chlamydia trachomatis infections in women with urogenital symptons. Canadian Medical Association Journal 127:974-976, 1982.

25. Terho $P$, Neurman $O$. Chlamydial serum IgG, IgA and local $\lg A$ antibodies in patients with genital-tract infections measured by solid-phase radioimmunoassay. Journal of Medical Microbiology 14:77-87, 1981.

26. Vieira $S$. As tabelas de contingência. Introdução à bioestatística. 6ª edição, Ed. Campus, Rio de Janeiro, RJ, p. 191-203, 1989.

27. Warren R, Dwyer B, Plackett M, Pettit K, Rizvi N, Baker AM. Comparative evaluation of detection assays for Chlamydia trachomatis. Applied Microbiology 31:16631666, 1993.

28. Wentworsth B. Isolation of Chlamydia trachomatis by use of 5-iodo-2-deoxyuridine-treated cells. Applied Microbiology 27:912-916, 1974. 